The University of Maine

DigitalCommons@UMaine

Vocal Popular Sheet Music Collection

Public domain (may be downloaded in full)

1907

\title{
There is No Place Like Home
}

Jos. E. Howard

Composer

Hough

Lyricist

Adams

Lyricist

Follow this and additional works at: https://digitalcommons.library.umaine.edu/mmb-vp

\section{Recommended Citation}

Howard, Jos. E.; Hough; and Adams, "There is No Place Like Home" (1907). Vocal Popular Sheet Music Collection. Score 5367.

https://digitalcommons.library.umaine.edu/mmb-vp/5367

This Book is brought to you for free and open access by DigitalCommons@UMaine. It has been accepted for inclusion in Vocal Popular Sheet Music Collection by an authorized administrator of DigitalCommons@UMaine. For more information, please contact um.library.technical.services@maine.edu. 


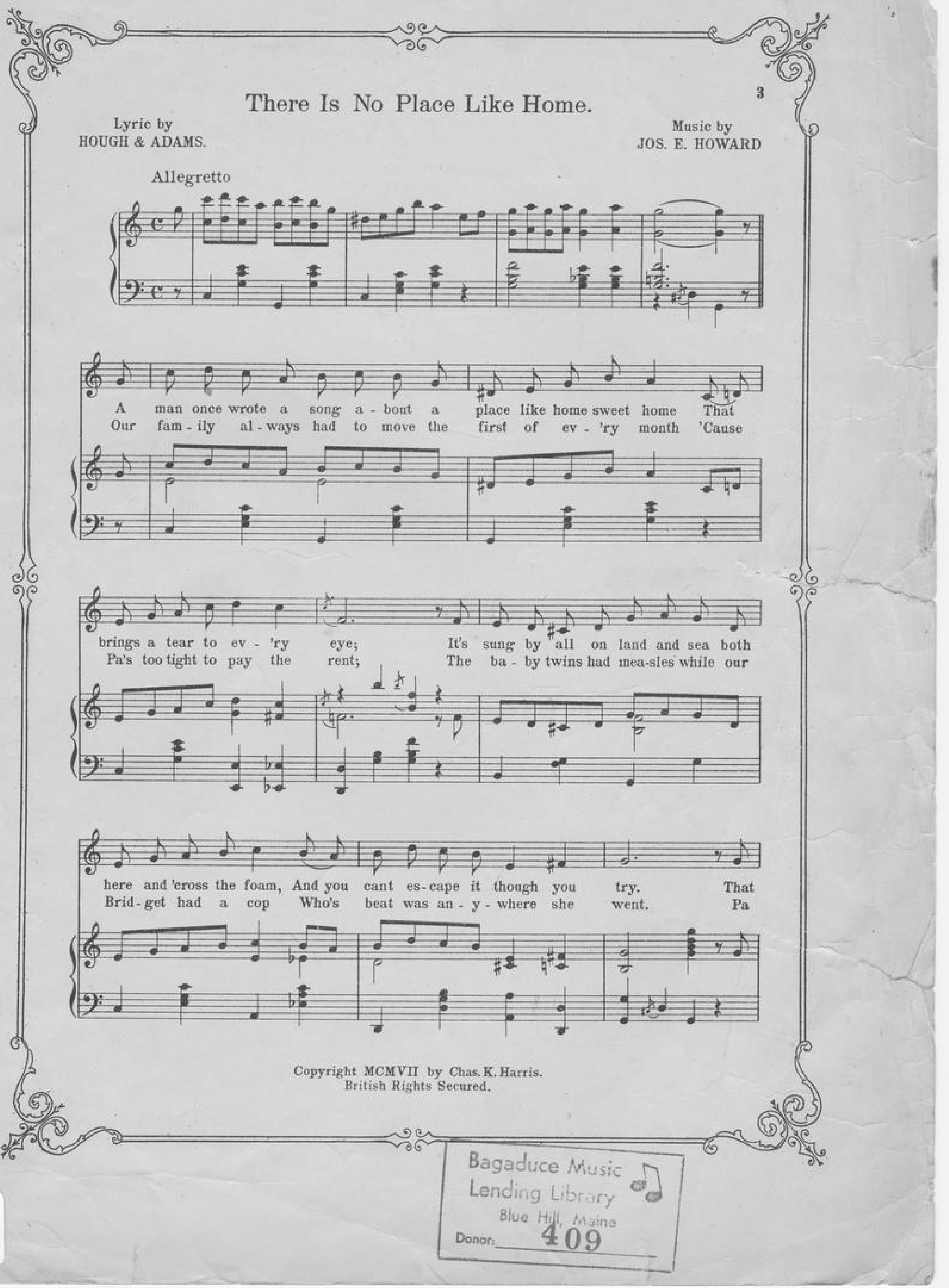




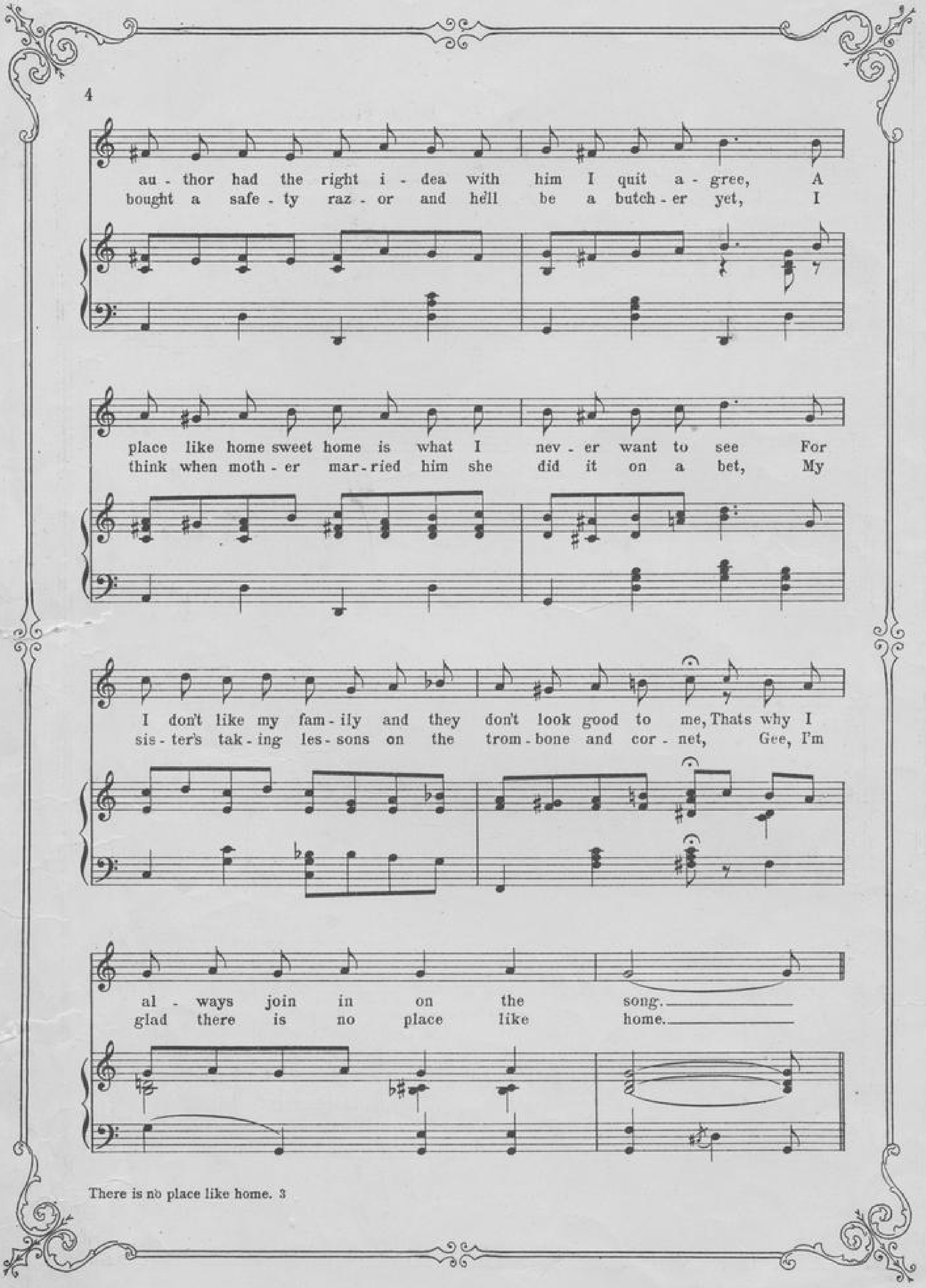




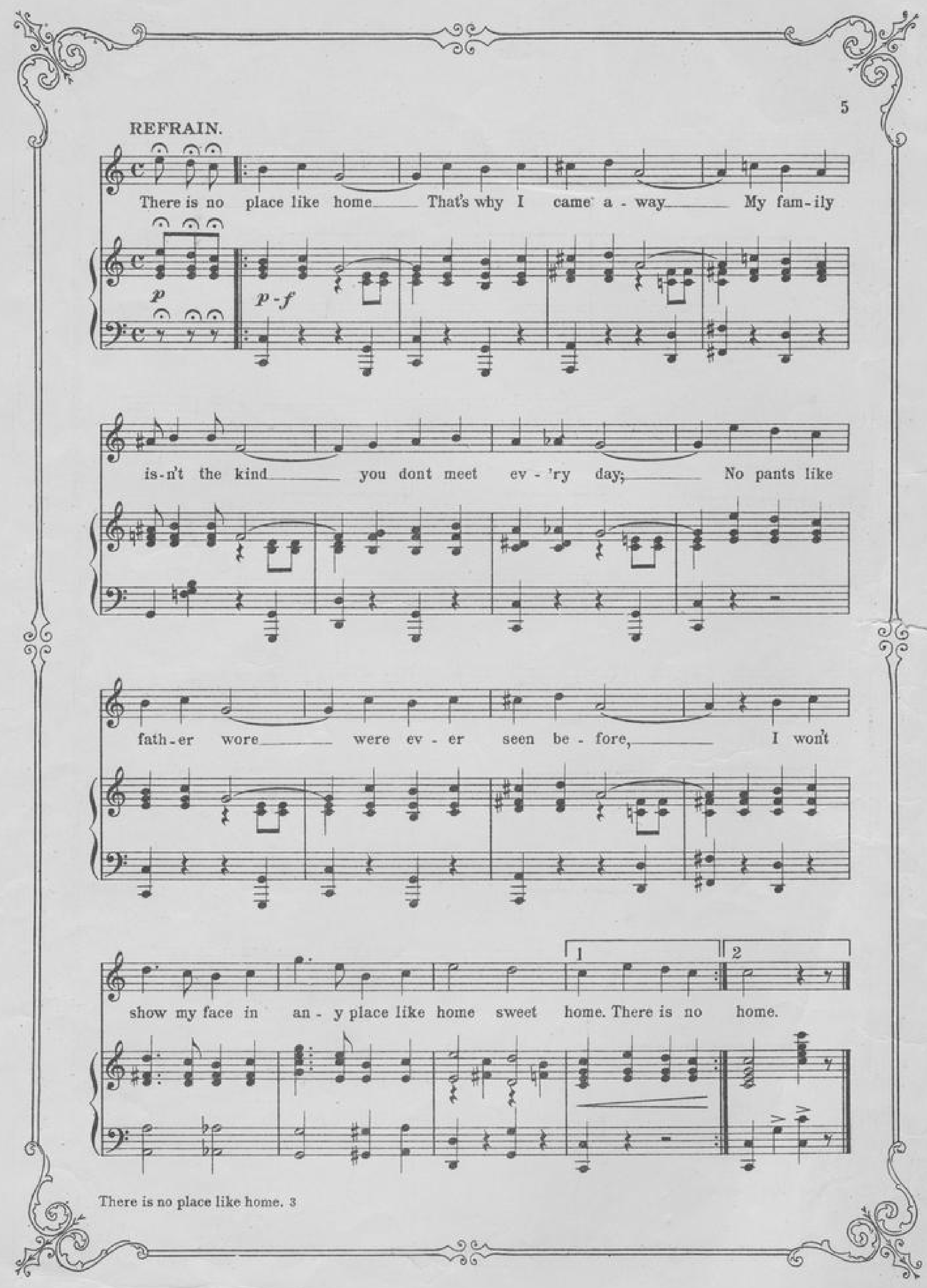

